\title{
The Rationalist Reply to Fodor's Analyticity and Circularity Challenge*
}

\author{
Víctor M. VERDEJO
}

Received: 1.6.2011

Final version: 22.2.2012

BIBLID [0495-4548 (2013) 28: 76; pp. 7-25]

ABSTRACT: The central Fodorian objections to Inferential Role Semantics (IRS) can be taken to include an 'Analyticity Challenge' and a 'Circularity Challenge', which are ultimately challenges to IRS explanations of concept possession. In this paper I present inferential role theories, critically examine those two challenges and point out two misunderstandings to which the challenges are exposed. I then state in detail a rationalist version of IRS and argue that this version meets the Fodorian challenges head on. If sound, this line of argument shows that there is no problem of principle in the consideration of IRS as a good candidate for a theory of concepts.

Keywords: analyticity; theoretical circularity; Rationalist IRS; Complete Frege Test.

RESUMEN: Las objeciones fodorianas en contra de una Semántica del Papel Inferencial (SPI) pueden concebirse como incluyendo un 'Reto de la Analiticidad' y un 'Reto de la Circularidad', los cuales son principalmente retos a las explicaciones que SPI proporciona sobre la posesión de conceptos. En este artículo presento las teorías del papel inferencial, examino críticamente estos retos y señalo dos malentendidos a los cuales están expuestos. A continuación, presento con detalle una versión racionalista de SPI y defiendo que esta versión supera los retos fodorianos directamente. Si es correcta, esta línea argumentativa muestra que no hay un problema de principio en la consideración de SPI como una buena candidata para una teoría de los conceptos.

Palabras clave: analiticidad; circularidad teórica; SPI Racionalista; Test de Frege Completo.

Jerry Fodor's battery of persuasive arguments against Inferential Role Semantics (IRS henceforth) or what he calls concept pragmatism (Fodor 2004, 2008) has at least one positive upshot in that it leaves one with the formidable task of providing a better insight into the relation between concepts, conceptual content, concept possession and explanatorily legitimate approaches to the mind. There are three clearly distinct lines of argument that Fodor and allies have launched against IRS, that is, the general thesis that concepts are accounted for in terms of the roles they play in the cognitive life of thinkers. The first is devoted to showing that such theories are incompatible with compositionality. The second argues that the theories only provide unprincipled explanations. The third denounces that any account along the lines of IRS is irremediably circular. While I hope to have provided the response to Fodor's first line of argument (Verdejo 2009a), in this paper I would like to examine and critically respond to

* Parts of this material were presented in the philosophy seminar at the Univesidade de Santiago de Compostela (USC). I would like to thank the members of the USC Faculty of Philosophy for their valuable and challenging feedback. I am also grateful to Concha Martínez, Christopher Evans and two anonymous referees for their contribution to improving central aspects of this work. This research has received financial support from the Ministerio de Economía y Competitividad of the Spanish government (research project FFI2009-08828/FISO), and from the Catalan government, via the consolidated research group GRECC (SGR2009-1528). 
both the second and the third. These lines of attack-which I will call the 'Analyticity Challenge' and the 'Circularity Challenge' respectively-are closely related. In a way to be seen shortly, they are both challenges to IRS accounts of concept possession.

Two important points of clarification will emerge in the critical examination of these Fodorian challenges. In the first place, and contrary to what other authors have strongly supposed, the 'Analyticity Challenge' is (who would have thought it!) not really about analyticity. Secondly, the Fodorian 'Circularity Challenge', although certainly about circularity, is not about what I term theoretical circularity, that is, the circularity that arises from equivalences in philosophical or scientific research. After characterizing IRS in some detail (Section 1), I will address these points about what really is at stake in Fodor's hostile arguments in Sections 2 and 3. In Section 4, I will offer a particular account of IRS, which (following the analysis in my Verdejo 2009a) I will call Rationalist IRS. In Sections 5 and 6, I will defend the idea that the propounded account offers a genuine kind of explanation in the theory of concepts. The moral shall be that, while Fodor can still be right that IRS or concept pragmatism is a "dead parrot" (Fodor 2004, 32), he is nonetheless wrong that it is so because of the unprincipled or circular character of the explanations it proposes. Since everything I discuss has to do with IRS, I will begin with a handy characterization of the theory.

\section{Setting the stage for Inferential Role Semantics}

The expressions 'Inferential Role Semantics' or 'Conceptual Role Semantics' or 'Functional Role Semantics' (IRS for short) refer to a family of theories that have as a central contention that conceptual content is determined, at least in part ${ }^{1}$, by the concept's role in the cognitive lives of thinkers. This thesis, which can be seen as stemming from the roughly Wittgensteinian motto that "meaning is use", has received different articulations. This is not the place to offer a detailed account of each possible theoretical alternative. In fact, I wish to focus on one specific version of IRS. Thus, here I will be arguing in favour of an IRS that has rationality as its fundamental explanatory notion. This makes my position closer to neo-Fregean accounts (Peacocke 1992, 2008; Wedgwood 2007). Alternative kinds of IRS include those versions that are more psychologically oriented (e.g., Block 1986; Harman 1987) or lead to so-called 'two-factor theories' of meaning (e.g., Block 1986; Loar 1982; Field 1977) or define inferential roles in syntactic terms (e.g., McLaughlin 1993; Rapaport 2002) or involve semantic approaches consonant with a deflationary view of truth (e.g., Horwich 1998, 2005) or privilege inferential roles over truth-conditions (e.g., Harman 1974) or simply explanatorily reduce truth to inferential norms (e.g., Brandom 1994). Nothing of what I will say in this paper should be automatically counted in favour of any of the alterna-

${ }^{1}$ The "at least in part" caveat points to the fact that inferential roles, if narrowly conceived, only provide a full account of conceptual content when completed with accounts of the reference of the concept-what Peacocke (1992) called a "Determination Theory of Reference". For ease of exposition and once this is clarified, I drop the caveat in what follows. Relatedly, it bears emphasizing that inferential roles are not taken to determine contents in the sense that contents just are inferential roles: what is essential to IRS is that conceptual contents supervene on inferential roles (see Greenberg and Harman 2006).

Theoria 76 (2013): 7-25 
tive kinds of IRS just mentioned. Nonetheless, it is my view that many of the considerations to follow could be counted as support of alternative kinds of IRS, insofar as they can either accommodate the role of rationality in neo-Fregean accounts or else invoke some other notion that is credited with an equivalent explanatory role (what exactly this role is will be the topic of Sections 4-6 below).

From the simple characterization just given above, it follows that, in the context of the theory of concepts, IRS is primarily a thesis about conceptual content. By general assent however, the inferential role of a concept $\mathrm{C}$-arguably together with the worldgives not only the content of $\mathrm{C}$ but also i) the individuation of $\mathrm{C}$ and ii) the possession conditions of $\mathrm{C}$. The first part of this assumption comes from the traditional view that concepts are (fully) individuated at the semantic level. Even if this view is not universally shared (see e.g., the informational position in Fodor 1998, 2008), it is clearly the rule rather than the exception. The second part of the target assumption is, even if perhaps not always explicitly stated (although see Peacocke 1992), the natural position to take in the context of an IRS. This can hardly be surprising. The central contention of IRS is, as advanced, that a concept $C$ inherits its content via its role in the cognitive life of a thinker. It follows rather directly that what subjects have to 'do' in order to possess $\mathrm{C}$ is just to instantiate C's specified conceptual role in their psychological economy.

The fact that standard IRS involves the twofold assumption just mentioned may be controversial in the light of accounts of concepts that reject the postulation of epistemic conditions for concept possession (e.g., Fodor 1998; Higginbotham 1998). There is, furthermore, no logical impossibility in conceiving an IRS in which this assumption does not hold. It is crucial, however, to note from the outset that the kind of IRS targeted in the Fodorian attacks is one for which these assumptions do hold. Thus, in the discussion to follow, for any subject $S$, concept $C$ and inferential role IR, IRS is committed to the following (a) and (b):

(a) A certain IR specifies the concept-individuating content of C.

(b) For $\mathrm{S}$ to have $\mathrm{C}$, is for $\mathrm{S}$ to instantiate IR in $\mathrm{S}$ 's cognitive life.

From these tenets it follows that, in the context of an IRS, issues concerning (concept-individuating) conceptual content are ipso facto issues concerning concept possession. With this broad characterization in mind, we are in a position to discuss the Fodorian challenges.

\section{The 'Analyticity Challenge'}

The Fodorian 'Analyticity Challenge' aims to show that there is a problem of principle in explaining conceptual content and concept possession via inferential roles (Fodor and Lepore 1991, 1992; Fodor 1998, 2004). This is the roughest outline of the challenge. According to IRS, the content of a concept is determined by the inferences in which it intervenes. Now, either all such inferences constitute the concept's content or else only a restricted set of them do. However, it cannot be that-according to a holist version of IRS - it is all the inferences that are content-constituting because-granted the idiosyncrasy of a subject's total inferential repertoire-contents of concepts pos- 
sessed by two or more different people could not possibly be considered as contents of the same concept - that is, (concept-individuating) conceptual content could not be publicly possessed. This is why, following Fodorian prospects, "holism is preposterous" (Fodor 2004, 36). ${ }^{2}$ On the other hand, if it is a restricted set of inferences that is content-constituting - according to a molecularist version of IRS - there must be a principled way of deciding or a definite criterion for specifying which inferences belong to the set and which do not. However, the only way available to an IRS for doing that is by appealing to one form or other of the analytic-synthetic distinction. Alas, this distinction cannot resist the well-known Quinean criticism. Therefore, molecularist IRS is fairly certainly not correct given the impossibility of providing a principled account (see Fodor 2004, 35, for a succinct exposition of this train of thought).

In this paper I would like to offer a response to this challenge (see Section 5 below). I must now make it clear that, despite powerful appearances to the contrary, there is very little reason to think that Fodor and allies' real 'Analyticity Challenge' is precisely a challenge about analyticity, that is, a challenge about the notion of truth or validity in virtue of meaning. Instead, the Fodorian concern must be, really, with a principled notion of content as accounted for by IRS theorists. In other words, given a concept $\mathrm{C}$, and a content-constituting inferential role CIR, the proponent of IRS must appeal to some definite non-stipulative criterion for the fixation of CIR. However, we can, and arguably we should, assess the principleness in question without bothering much about whether such principleness relies on analyticity or not. If true, the claim is important and it amounts to identifying one of the biggest distractions possible in the discussion of concepts. Since, furthermore, this is news for authors who, in the light of the Fodorian challenge, try to formulate a satisfactory notion of analyticity (e.g., Boghossian 1993, 1997; Rives 2009a), it is worth articulating in some detail the justification of this claim.

To begin with, and remarkably enough, in this particular dialectical context, nobody-not even the Fodorian - really relies on Quine's developments in "Two Dogmas of Empiricism" (1951), let alone on Quine's developments regarding the rejection of the analytic/synthetic distinction. As regards Fodorian developments, there are several places where it is simply obvious that the Fodorian dialectical stance is very much not Quine's; indeed, that Fodorians must take much care when they go shopping in the Quinean market. ${ }^{3}$ More importantly, there is a remarkably wide consensus that, whatever Quine actually showed in "Two Dogmas", he did not show that there is

\footnotetext{
${ }^{2}$ For some theorists at least (see e.g., Block 1995; Bilgrami 1998), holism is a perfectly respectable alternative, one worth arguing for. For present purposes however, I will just grant Fodor's contention.

${ }^{3}$ Here I refer to such theoretical niceties as Quine's position in “Two Dogmas" involving: 1) a holism of confirmation which - under a verificationist conception of meaning-leads to semantic holism; 2) a strong connection, and arguably an inescapable one (cf. Boghossian 1997; Rattan 2008), to the indeterminacy thesis defended in his Word and Object (1960, chap. 2); or 3) an attempt to "draw ontological conclusions from epistemic premises" (Fodor 2004, 35). All these Quinean views are of course unpalatable itches for a good Fodorian and so they receive different scratches. Detailed discussion should be left for another occasion.
}

Theoria 76 (2013): 7-25 
no workable, philosophically respectable notion of analyticity. ${ }^{4}$ Several authors have proposed notions of analyticity that allegedly escape the clutches of the Quinean critique, whatever the precise interpretation of such a critique may be. In effect, the thesis that there is some respectable notion of analyticity, even after Quine's celebrated attack in 'Two Dogmas', is a thesis shared by authors of practically all flavours (e.g., Grice and Strawson 1956; Putnam 1975; Sober 2000). These include authors both unsympathetic (e.g., Boghossian 1997) and (remarkably enough) sympathetic (e.g., Rives 2009a) to Fodor's atomistic view of concepts. They also include (more remarkably still) Fodor's own developments. Thus, for instance, Fodor (1998, chap. 4) spells out a notion of analyticity based on semantic intuitions, precisely the ones that Fodor's Informational Atomism may explain away by appeal to Putnam's one-criterionhood. Another, not less important, instance of 'Fodorian analyticity' is found in Fodor's purely referentialist approach to Frege cases. The target notion of analyticity is based upon syntactic properties of representations, as opposed to its semantic properties (Fodor 2008, 71). All this shows that, even by Fodorian lights, there is some respectable notion of analyticity. It seems quite clear therefore that no-one here-not even the Fodorian-is really relying on Quine's critical views, let alone Quine's critical views on the analytic-synthetic distinction.

Leaving aside Quine's developments, two further sorts of reflections show that analyticity is not the real issue at stake in the 'Analyticity Challenge'. On the one hand, a notion of analyticity seems pretty much inescapable from the point of view of realism about meaning and conceptual content. This is so even if we grant the illegitimacy of the notion of truth or validity in virtue of meaning as an explanatory notion. To a very rough approximation, if $\mathrm{M}$ is your candidate for the meaning of $\mathrm{C}$, then the fact that $\mathrm{C}$ means $\mathrm{M}$ is, according to your theory, a truth in virtue of the meaning of $\mathrm{C}$. If devoid of any explanatory weight, this is probably an innocent truism. Generally, any realist theory of meaning or conceptual content must acknowledge the existence of whatever truths the favoured theory allegedly puts forward and of whatever follows from those truths. They will be, in a very clear and innocent sense, truths in virtue of meaning or conceptual content. ${ }^{5}$

On the other hand, one would have thought that, if analyticity were the real issue in Fodor's challenge, then any defender of IRS would invariably be a defender of the (explanatory) notion of analyticity. However, we have a significant case in which nothing of the sort happens. Under Peacocke's articulation of IRS (Peacocke 2002, 2004a,

${ }^{4}$ In other words, we take it that "strictly speaking, Quine in 'Two Dogmas' did not show, or even argue, that there are no analytic truths" (Fodor and Lepore 1992, 57, their emphasis) or that "Quine didn't prove that you can't make sense of analyticity, definition and the like" (Fodor 1998, 46, his emphasis) and hence we can "doubt that Quine's sort of arguments, taken by themselves, are decisive against semantic molecularism [or IRS]” (Fodor 2004, 35).

${ }^{5}$ Cf. Boghossian's illuminating remark that meaning realism ensures the existence of analytic inferences (Boghossian 1993, 80). Here I extend Boghossian's point about inferences to any meaning facts to which a realist theory is inescapably committed. However, since I am denying analyticity, so considered, any explanatory role, I am also denying its explanatory role regarding knowledge of a priori truths and hence I am not here buying in on Boghossian's (1997) notion of epistemic analyticity. 
2004b), the account of concepts is intrinsically connected to the notion of the a priori. However, the notion of the a priori "should not be involved with the uninstantiated and uninstantiable notion of 'true in virtue of meaning"' (Peacocke 2002, 377).6 If Peacocke and Fodor agree on the rejection of analyticity, then analyticity is clearly shown to be orthogonal to the IRS debate.

The foregoing considerations are not considerations to the effect that there cannot be a notion of analyticity that might be relevant for assessing the Fodorian challenge. A theorist might try to formulate or argue for the legitimacy of such a notion, one that is not (a simple version of) the notion of truth or validity in virtue of meaning. I am quite prepared to concede that there might be some such notion of analyticity. Nonetheless, the line of argument presented above clearly shows that, even if one could get to a relevant notion of analyticity, assessment of the Fodorian challenge and of the legitimacy of analyticity are projects that are quite independent of one another. Indeed, the requirement that the notion of content be principled is a requirement that one must face even if and even though one rejects/accepts some version of the notion of analyticity. In this context, it seems quite reasonable therefore just to abandon the query about the notion of analyticity and ask directly: can an IRS come up with a notion of content that is principled? Before answering this question, however, I would like to examine Fodor's newest objection to IRS.

\section{The 'Circularity Challenge'}

Fodor $(2004,32)$ presents what I call the 'Circularity Challenge' as being a new argument that he has recently formulated (see Fodor 2004, 40-46 for the presentation of this argument). Recent as it is, there are nonetheless different versions in circulation. ${ }^{7}$ For present purposes, we can summarize the challenge thus. Take the inferential role (IR) of a concept C. Let us assume, for the sake of the argument, that IR correctly specifies the content of C. Fodor's contention is then that, in order for IR to also specify the putative possession conditions for $\mathrm{C}$, it must invariably presuppose possession of $\mathrm{C}$ on the part of the subject. The reason is that for IR to constitute C's possession conditions is for IR to be provided by reference to C's role in a subject's cognitive life. However, one cannot consider C's role in a subject's cognitive life without thereby assuming that the target subject understands or grasps $\mathrm{C}$, or somehow represents the content of C. In other words, even if inferential roles can satisfactorily give an account of conceptual content, as soon as one tries to extract from it an account of concept possession "vicious circularities arise" (Fodor 2004, 46).

${ }^{6}$ See also Peacocke 2004b, 92-93. Another significant case of rejection of analyticity from the point of view of an IRS defender is found in Harman (1999, chap. 5). Note in passing that Peacocke's commitment to the notion of a priori is not one I would like to pursue here (see Section 4).

${ }^{7}$ In what follows, I ignore Fodor's less central circularity considerations with regards to sorting capacities (Fodor 2004, 39-40), to dispositional accounts of rule following (Fodor 2008, 34-40) and to the notion of computation (Fodor 1998, 9-12). The circularity involved in accounts of sorting and dispositional rule following can be understood as particular instances of the general case presented in the main text. The circularity attack based upon the very notion of computation is quite a different sort of objection and need not concern us here. I address this last objection in Verdejo (2009b, chap. 3).

Theoria 76 (2013): 7-25 
Remarkably, this objection is also meant to apply to cases where IRS seemed at first more secure, namely, cases of logical constants such as conjunction. If sound, it would force us to conclude that IRS is not even correct for logical constant concepts and "then it would seem that there are no examples on offer of how the conceptual role of an expression might determine its content and its possession condition" (Fodor 2004, 42).

Before delving into a response to Fodor's challenge, it is important to note that Fodor is not as clear as he might be on how we should understand the 'Circularity Challenge'. At some points, Fodor misleadingly suggests that the questionable circularity has to do with the fact that IRS precisely formulates accounts that explain at the same time content and possession conditions of concepts. For instance, in the following passage:

Here's what I take to be the source of the problem. The basic idea [of IRS] is that implicit definition [of e.g., logical connectives] can specify a concept's inferential role and thereby determine its possession condition. But, even if you like inferential role semantics, you might well wonder whether any one stone could kill both these birds. After all, the inferential role of a concept has to do with which of the arguments it's involved in are valid. Whereas which concepts a creature possess depends on what mental state it's in. In consequence, the constraints on formulations of possession conditions are arguably quite different from the constraints on implicit definitions. (Fodor 2004, 42; emphasis his)

In my view, Fodor's considerations in this context are quite beside the point. For the point is not whether IRS is circular because it integrates accounts of conceptual content-via suitable inferential roles—and concept possession. Indeed, the kind of circularity that one might think Fodor is worried about here is of a harmless kind. It is an instance of what I dub for present purposes theoretical circularity. In order to see clearly what goes under the label of theoretical circularity it is helpful to consider the following example from economics.

After a brief examination of the manuals on the subject, one can readily appreciate that standard doctrine in macroeconomics defines gross domestic product (GDP) as the total amount of goods and services in a given territory over a period of time- the commonly accepted measure of what Adam Smith called "the wealth of nations". A closer look at the manuals can make one appreciate further that the notion of GDP conceals three very interesting equivalences. On the one hand, we can understand GDP as being a function of the demand of a given country, that is, the sum of all the spending on goods and services within the economy. Secondly, a country's GDP can be taken, from the point of view of the income, to be the total of incomes earned in the economy. Finally, from the perspective of the output, GDP is conceived to be the total value added by the goods and services produced in a given territory. Scientifically respectable prejudice in macroeconomics therefore has it that there is theoretical circularity in usual estimations of GDP: macroeconomic production, aggregate demand and income are explained in terms of one another. Thus, one cannot compute the total production of goods and services of a given country over a given time without thereby calculating the total expenditure on such goods and services, and the total income generated in the production of those goods and services. This is so even if, ob- 
viously enough, demand, production and income are different sorts of things and clearly depend on quite different sorts of factors.

As the reader may suppose, I do not think it would be a good idea to quibble over theoretical circularity. This kind of circularity is ubiquitous in respectable science. All you need to have an instance of it is an (empirically grounded) equivalence. Roughly, if $\mathrm{A}=\mathrm{B}$, then it follows very closely that to say what $\mathrm{A}$ is, amounts to saying what $\mathrm{B}$ is (and the other way around). Not an easy thing to worry about. But this parallels the IRS case that concerns us here. From the quotation above, and following standard formulations of IRS (see Section 1), we should accept that the basic idea underlying IRS is that "implicit definition [of paradigmatically, logical connectives] can specify a concept's inferential role and thereby determine its possession condition". And we can grant that one "might well wonder whether any one stone can kill both these birds [viz. conceptual content and concept possession]". Furthermore, it is also true that "the constraints on formulations of possession conditions are arguably quite different from the constraints on implicit definitions". From all this however, it does not even begin to follow that IRS is relying on a kind of circularity that goes beyond harmless theoretical circularity, a very weak basis indeed on which to embarrass an IRS.

Of course, we take it that Fodor is not (or should not be) concerned with theoretical circularity. He claims that IRS or concept pragmatism promotes a kind of "vicious circularity" (Fodor 2004, 39). On the face of it, theoretical circularity is not of a (scientifically regrettable) vicious sort. In contrast, the kind of circularity Fodor must have in mind is what I call explanatory circularity. Roughly, explanatory circularity takes place when in order to explain X one, shamelessly or however inadvertently, presupposes X. The Fodorian idea seems to be that if one explains, via inferences, what it is to possess the concept $\mathrm{C}$, the theorist glaringly presupposes possession of $\mathrm{C}$.

In the next section I begin to address the Fodorian challenges. The reader may realize at this point that there is a way of meeting both challenges head on. In particular, if we can articulate a genuine kind of explanation (of conceptual content and concept possession) within inferential role theories, we would presumably have responded to both Fodorian challenges. The kind of account I am about to present is neither new, nor one that can convince the Fodorian that his own informational approach to concepts is wrong. It is however one whose power and broad generality have not been sufficiently emphasized as a response to the Fodorian criticisms. It is also one that should convince the Fodorian to give up, once and for all, on the validity of the challenges under consideration.

\section{Rationalist IRS}

In Section 1, I characterized IRS as involving the following two commitments regarding any subject $S$, concept $C$, and inferential role IR.

(a) A certain IR specifies the concept-individuating content of C.

(b) For $\mathrm{S}$ to have $\mathrm{C}$, is for $\mathrm{S}$ to instantiate IR in S's cognitive life. 
Following the neo-Fregean approaches of authors such as Peacocke (1992), Evans (1982), McDowell (1994) and Wedgwood (2007), I add the following rationalist thesis (RT) to the general IRS picture:

(RT) The IR associated with a concept $\mathrm{C}$ must be specified in terms of the role the concept plays in the cognitive life of a rational subject $\mathrm{S}$.

Thus, the target kind of IRS appeals centrally to the notion of rationality and, more precisely, to the notion of Rational Inferential Role (RIR for short). When added to the general characterization of IRS, (RT) results in the substantial, non-speculative thesis that the inferential role relevant for determining conceptual content and concept possession must be an inferential role that respects (and hopefully completely accommodates) the cognitive situation of rational subjects who have the target concepts. We can get a more precise idea of what this means via consideration of the Frege tests associated with a concept C. ${ }^{8}$ Take a pair of thoughts that differ only in that one contains the concept $\mathrm{C}$ while the other contains the concept $\mathrm{C}^{\prime}$. A Frege test evaluates whether $C$ and $C^{\prime}$ are the same or different concepts, depending on whether a rational subject can accept one of the thoughts while still rejecting or being agnostic about the other (in which case they would be different concepts); or whether a rational subject cannot accept one and still not accept the other (in which case they would be the very same concept). In addition, and for our purposes, it is useful to define a Complete Frege Test (CFT) for a concept $C$ as the set of all the Frege tests that would completely account for the RIR of C. The idea is that a CFT would provide us with the whole range of propositional contents containing a particular concept $\mathrm{C}$ that a rational subject would be in a position to accept, granted that this subject has C. Given a concept $\mathrm{C}$, then, the RIR of $\mathrm{C}$ is constituted by the set of $\mathrm{C}$-containing propositional contents which a rational subject who possesses $\mathrm{C}$ would accept if the question arose or, in other words, all the C-containing propositional contents identified in the CFT for C.

The idea underlying this characterization is simple once it is put to work. Consider, for instance, the concept Hesperus, the conceptual counterpart of our singular term 'Hesperus'. Now, a good specification of the RIR associated with Hesperus must include all the propositional contents that a subject is in a position to accept, in virtue of that subject being rational and possessing the concept. Thus, for instance, the target inferential role should include such facts as that any rational subject that possesses Hesperus would accept the propositional content That is Hesperus when perceptually

\footnotetext{
${ }^{8}$ The consideration of Frege cases does not, in and of itself, involve an IRS, let alone a Rationalist IRS. It is open to a theorist to argue, for instance, that the accommodation of Frege cases, exhibited in Frege tests, can be made without appeal to the (semantic) notion of Fregean sense via a syntactically characterized notion of mode of presentation (e.g., Fodor 1998, chap. 1; 2008, chap. 3). However, and even though I cannot elaborate the point further here, I am sceptical about the very consistency of a position that accepts the individuation of concepts at the level of Fregean sense and yet denies that concepts are individuated by considerations of rationality. See Rives (2009b) for a defence of a position along these lines. This position is closely related to Rives' own account of analyticity in terms of Carnapian meaning postulates (Rives 2009a). Suffice it to say that, in my view, if rationality-or some other notion playing its role-is not present to explanatorily support the semantic individuation of a concept (in terms of its RIR), it is hard to see what it would do in a non-question begging way.
} 
confronted with such and such heavenly body in such and such position in the sky in the evening. Similarly, the target inferential role would include such transitions in thought as the one that goes from the propositional content That is Hesperus to That is a beavenly body or That is in the sky, or That is the evening star, etc. ${ }^{9}$ It follows from thisand from standard Fregean doctrine- - that the RIR for Hesperus will exclude thought transitions that go from That is Hesperus to That is Phosphorus. The very familiar reason for this exclusion is that a rational subject may accept the former while doubting or rejecting the latter.

By way of further illustration, let us consider the case of the concept water. A correct RIR for water would include, as part of its cognitive role, acceptance of the propositional content This is water when perceptually confronted with the liquid that fills rivers, lakes, oceans and Jacuzzis on the Earth. In a similar vein, the water-RIR would include the transition from This is water to This is odourless, This is transparent, etc. However, from among the thought transitions included in the water-RIR, the one that goes from This is water to This is $\mathrm{H}_{2} \mathrm{O}$ is likely to be missing. The reason is that a rational subject who believes the former, could still doubt or reject the latter.

The reader may note that the considerations above are very general, even if the analysis of different concepts may result in very different kinds of RIRs. For example, the concepts of logical connectives may be based upon Gentzen calculus and result in a general form of inference as their RIRs (instead of an account in terms of a particular set of (partially perceptual) inferences as in the cases of Hesperus and water). The relevant roles of indexical concepts (such as I or here), abstract concepts (such as number or belief), moral concepts (such as justice or goodness) or ordinary concepts (such as chair or doorknob) may also differ greatly. The details-both of conceptual taxonomy and of the particular accounts for each concept-can, of course, be astonishingly hard to complete. Fortunately, we do not need a full explanation for the purposes of this paper. It is enough that we note that, from a theoretical point of view, an account in terms of a rational IRS is conceivable and plausible. Indeed, a Rationalist IRS can invoke the notion of rationality in a non-trivial way (that is, via suitable CFTs) and hence offer a promising delineation of an IRS framework.

Notably, the notion of rationality at stake in this account does not, in and of itself, involve a commitment to the notion of the a priori or to the general view that "once the issues are properly formulated, all entitlement has a fundamentally a priori character" (Peacocke 2004a, 2). A Rationalist IRS as understood here owes no reverence to traditional rationalist approaches for which the notion of a priori was fundamental. According to the propounded account, rationality is articulated in terms of Fregean

\footnotetext{
${ }^{9}$ It is worth emphasizing that the transitions that may constitute the RIR of a concept $\mathrm{C}$ are not, in the general case, exhausted by (even if they obviously include) the transitions read off from a concept's syntactic structure. Thus, obviously, the RIR of the evening star includes transitions from This is the evening star to This is a star - and similarly for brown cow, red tomato and global crisis. But although a concept's compositional structure can be of help in determining the inferential role of a complex concept, it is of no help at all in the elucidation of the inferential role of primitive concepts (see Rives 2009a for a similar point).
} 
cognitive significance. Whether one takes this notion to be highlighted better in terms of a priori or a posteriori entitlement is a further theoretical question.

We can summarize the presented account in terms of two central theses regarding any concept $C$, subject $S$, and rational inferential role RIR.

(a) A certain RIR—stated via a Complete Frege Test (CFT)—specifies the content of $\mathrm{C}$.

(b) For $\mathrm{S}$ to have $\mathrm{C}$, is for $\mathrm{S}$ to instantiate RIR in S's cognitive life.

Now, I am highly inclined to believe (and therefore I am prepared to vehemently argue) that a Rationalist IRS along the lines presented here is neither unprincipled nor circular, and hence that it can meet the Fodorian challenges outlined above.

\section{Principled IRS}

The account I have been giving leads us to obtain a definite notion of conceptual content and concept possession, one that allows the proper specification of the rational capacities associated with a given concept. When those rational capacities are inferential capacities, a Rationalist IRS does give a principled criterion for deciding which inferences are content-constituting and which are not. From a general point of view, that criterion corresponds to the individuation of a concept at the level of Fregean sense. More specifically, the proposed criterion is the result of applying, in a comprehensive way, the Frege tests associated with a given concept $C$ which provide the correct RIR for $\mathrm{C}$.

One can have, no doubt, infinite concerns about the propounded kind of theory. Among them, however, we should not reasonably expect to find the concern that such a framework is unprincipled. When we say that a certain transition must be included in or excluded from the RIR of a concept $\mathrm{C}$, we are not making an arbitrary contention or proclaiming the legitimacy of a mere stipulation. The precise statement of the RIR for $\mathrm{C}$ has to do with the overarching fact that rational subjects that possess the concept just engage (or do not engage) in the target transitions. Explanation in Rationalist IRS is provided via appeal to the notion of rationality and to the testable facts surrounding that notion. This is not, I submit, an illegitimate appeal, such as the appeal a theorist may make to the notion of analyticity. In contrast, the notion of rationality is precisely articulated here in terms of the results of Frege tests when applied to Ccontaining propositional contents. In this context, to deny legitimacy to the Rationalist IRS account just provided would amount to denying legitimacy to the very conceptindividuating notion of sense widely accepted among philosophers. Thus, when we refrain from including the transition that goes from This is Hesperus to This is Phosphorus in the RIR for Hesperus, we are doing so on the basis of rationality. This basis allows us, for instance, to distinguish indefinitely many pairs of co-referential concepts: Cicero/Tully, Aristotle/The tutor of Alexander the Great, Animal with a heart/Animal with a kidney, Gold/Mineral with atomic number 79, and a very long etcetera. Our exclusion of the target transitions is not a fancy of our (Fregean) imagination but has to do with the analysis of deep facts concerning the rational capacities associated with our concepts. 
Scepticism with regard to the principled character of Rationalist IRS may stem from appreciation of some uncomfortable facts that I would like to highlight in the remainder of this section. These facts are, in my view, facts that any theory of conceptual content must live with. Nonetheless, they fall short of grounding any accusation of being unprincipled. Thus for instance, Rationalist IRS must, in the first place, live with the difficult statement of full accounts. The task of providing the full RIR corresponding to a given concept is often not the easiest thing to do. To be sure, the most promising field for finding RIRs is that constituted by logical connectives and other syncategorematic expressions. Beyond these cases, it may be very hard to find a ready inferential schema that successfully defines the CFT associated with a given concept. The notion of CFT for a concept $\mathrm{C}$ is, according to the present considerations, an idealization that gives us, more often than not, only a heuristics of the kind of account that would be most satisfactory once one is involved in the project of constructing a Rationalist IRS. It would be naïve to suppose that full accounts will always be available. This is nothing like the claim that IRS accounts are unprincipled in the disastrous way the Fodorian presumes. In particular, IRS seems here not to be worse off than any other kind of functionalist account. The problem of providing full accounts is presumably the problem for any functional analysis. It is therefore only to be expected that the functionalist kind of account that IRS promotes regarding concepts has, at the very minimum, the same problems as functionalism tout court. ${ }^{10}$ The usual absence of full accounts of the IRS of a concept should not make us conclude that such accounts are irremediably unprincipled.

The situation for IRS is aggravated because we not only usually lack a full account, but furthermore we can simply be wrong, and in some cases seriously wrong, about the content-constituting transitions for a given concept. The reason for this is (shame on us!) that we do not infallibly intuit the inferential roles that individuate concepts. Nonetheless, the fact that there is a clear possibility of error in the proper statement of the RIR for a concept $\mathrm{C}$ is intrinsically connected to the fact that people may frequently engage in incorrect inferential patterns regarding $\mathrm{C}$ or in misapplications of $\mathrm{C}$. In the light of this, it seems reasonable to conclude that positive assessment of the principleness of the explanations of a Rationalist IRS requires a criterion for distinguishing (not only content-constituting inferences from the rest but also) mere incidental error (compatible with possession of $\mathrm{C}$ ) from genuine irrationality (incompatible with possession of C). ${ }^{11}$

The Rationalist IRS framework offers a rationale for distinguishing (not only two but) at least three clearly distinct kinds of case in which subjects may instantiate (in their cognitive lives) an incorrect transition from a true thought $\mathrm{T}$, to a false thought T', where both $\mathrm{T}$ and $\mathrm{T}$ ' contain a concept $\mathrm{C}$ as a constituent. To a first approximation, this rationale is based upon reflection as to whether the fact that subjects make

10 A particularly clear example of this is the current 'variability debate' among neuroscientists about the very possibility of full functional characterizations of areas of the brain — such as paradigmatically Broca's area. See Grodzinsky and Santi (2008) for a recent overview of the available functional analysis of Broca's area.

${ }^{11}$ I owe this point to an anonymous referee for this journal. 
such invalid transitions is compatible with their having a plausible cognitive value that would make such transitions rational. First, thinkers may make the transition even if they possess full mastery of the concept C. For instance, a subject may accept as valid a transition from That is the evening star to That is not the morning star. Instantiating some such transition would be rational simply because the cognitive value associated with The evening star is (following standard Fregean doctrine) distinct from the cognitive value associated with The morning star. Secondly, thinkers may make the transition because they have partial understanding/misunderstanding of C. For instance, Bert may correctly believe that Arthritis is a rheumatoid disease and somehow infer wrongly that People may have arthritis in their thighs. Following standard anti-individualist doctrine, when Bert's individual history is appropriate, this is a case in which Bert possesses arthritis but does so by virtue of the relation to his social environment. Bert can thus be attributed the right cognitive value for arthritis in a way that makes him rational in spite of his mistaken transition. Critical thinking and non-standard theorizing are also instances of this second kind of case. Following Burge's $(1986,716)$ analysis, we can attribute the right cognitive value for atom to Dalton in spite of his instantiating the transition from This is an atom to This is indivisible. In general, partial understanding of $\mathrm{C}$ and wrong thinking involving $\mathrm{C}$ are, when the appropriate individual and external conditions hold, clearly compatible with rational possession of C. Finally, thinkers may make the transition in such a way that no suitable cognitive value would plausibly make it compatible with the thinker's rationality. A person's sincerely carrying out transitions from This is a carburettor to This lives in the African veld, or from This is red to This is not coloured indicates that this person instantiates the third case regarding the concepts carburettor and red. To be sure, all this needs refining. Particular examples and limiting cases could make it hard to decide, sometimes, whether a given inferential pattern belongs to one or other of these three kinds of case. We can still confidently claim to have a definite criterion for telling the distinct cases apart, based on the attribution of appropriate cognitive values.

Comfort with our RIRs is further put to the test by the existence of deep theoretical questions for which we lack a ready answer. A central example of this is the existence of so-called Mates cases (Mates 1952). These are cases of indirect propositional attribution that putatively show that synonym expressions-such as 'bachelor' and 'unmarried man'-do not pass the Frege test associated with those expressions. It is for example possible that Oscar accepts that Jack believes that John is a bachelor while still doubting whether Jack believes that John is an unmarried man. A number of different solutions have been given, from a Fregean point of view, to Mates cases. These include restrictions on the application of Frege tests (Peacocke 2000) and a particular semantics for 'that'-clauses (Pietroski 2000). Apart from specific developments, this shows that there are deep theoretical questions that await the proponent of RIRs. The existence of such theoretical problems, however, cannot warrant the accusation that explanations of a Rationalist IRS are unprincipled.

In short, accounts along the lines of a Rationalist IRS are hard to complete, certainly fallible and subject to problematic theoretical questions. Give or take a bit, these are all bad news for Rationalist IRS. Even in the implausible case in which these are 
problems specific to a Rationalist IRS, they fall short of being the devastating problem that such accounts are unprincipled; that is, that they do not provide a definite criterion for the individuation of conceptual content and concept possession. Now, on the assumption that all this is more or less correct, there is of course the possibility of attacking IRS on the basis that it amounts to unpalatably circular accounts.

\section{Non-circular IRS}

From the previous discussion (Section 3), we are in a position to note that Fodor's accusation of circularity does not (or at any rate should not) concern what I have called theoretical circularity, namely, the circularity that arises from theoretical equivalences. The circularity threat to IRS accounts of concept possession must therefore be considered in terms of explanatory circularity, that is, the type that holds when, in order to explain some phenomenon X, we presuppose X. It might seem that there is firm ground for such an accusation. The proposed characterization of IRS maintains that for a subject to posses $\mathrm{C}$, is for that subject to instantiate a RIR in his or her cognitive life, where the RIR is determined by the role the concept plays in a rational mind that possesses the concept. Explanatory circularity might seem pretty obviously present for the Fodorian to see. According to this interpretation, we are faced with an instance of an account of roughly the following form:

For $\mathrm{S}$ to have $\mathrm{C}$, is for $\mathrm{S}$ to accommodate the workings of a mind that has $\mathrm{C}$.

This reading of the characterization of Rationalist IRS is however, not merely uncharitable, it is clearly wrong. The crucial point is that the expression "having C" in each of its occurrences in this schema is not to be interpreted as operating under the same description. The second occurrence of the expression "having C", but not the first, is constrained by the requirement that it is a rational subject that possesses the concept. In other words, the general explanation of concept possession proposed by (Rationalist) IRS is one in which concept possession in general is explanatorily reduced to rationally constrained concept possession. This rationality requirement has substantial consequences for the account of concepts. When considering the quite different issue of compositionality, it crystallizes in the specific requirement that inferential roles must fix a condition for something to be the semantic value of the concept (see Verdejo 2009a). The regulative role that the notion of rationality plays for our present purposes can be stated through the following lemma: not just any situation in which a subject may be taken to exhibit possession of $\mathrm{C}$ is a situation in which a subject instantiates the inferential role of a rational subject that actually possesses $C$. The latter, rational notion of possession is far narrower than the former.

The Fodorian contender may wish to reply by emphasizing that the appeal to a rationally constrained notion of concept possession in explanations of concept possession is useless because such a notion involves, inter alia, possession of C. Someone capable of instantiating the RIR for $\mathrm{C}$ is someone who rationally understands $\mathrm{C}$, or grasps C, or somehow mentally represents C. Circularity, the Fodorian would conclude, is still with us. 
In reply, the defender of Rationalist IRS must insist that the circularity in question would be in order only if the notion of concept possession involved in the articulation of the RIRs for $\mathrm{C}$ was the very same notion of concept possession that it aimed to explain. As it happens it is not; thus no circularity is justly attributed to such accounts. Any account along the lines of a Rationalist IRS offers an explanation in terms of the inferences or judgemental schemas that capture the Fregean cognitive value associated with the concept and very much not an explanation in terms of the general, pretheoretical or commonsense notion of concept possession. Such explanations have a maximally informative character. This is illustrated by the variety of forms that a Rationalist IRS can take. As is well known, they can consist of or heavily draw on, an implicit definition (of, e.g., a logical connective) (Peacocke 1992; Boghossian 1997). They can also involve transitions from perceptual states to certain judgments, as in the case of observational concepts such as red or square (Peacocke 1992) or partially observational concepts such as brown cow (Verdejo 2009a). Alternatively they may specify the role of a concept as a consequence of the appreciation of the correctness of a certain identity statement (Peacocke 2008, esp. ch. 5), or of certain definition, or implicit conception, involving the concept (Peacocke 1998; 2008, ch. 4). Yet again, in some cases, these roles can be interpreted as a consequence of sensitivity to the normativity constitutively associated with the concept (Wedgwood 2007, esp. ch. 4). None of these accounts presuppose the notion of concept possession as it appears in the relevant explananda. These are not vacuous or self-satisfying accounts of the kind ridiculed by Molière's vis dormitiva. Far from it, they are attempts to explanatorily reduce the general unexplained notion of possession or grasp or understanding of $C$ in terms of an (eventually extremely complex) analysis of the roles that $C$ plays in the cognitive economy of a rational thinker. ${ }^{12}$

At this point, the Fodorian may still wish to stress that intentional notions of the sort appealed to within Rationalist IRS are not really explanatory at all. A real explanation needs a reduction not to some (rationalist) inferential role at the intentional level, but to some other, non-intentional vocabulary. ${ }^{13}$ It is only because the defender of Rationalist IRS aims to provide intentional explanations that this defender thinks he or she may succeed in the project of achieving explanations of concept possession. However, the Fodorian could argue that in trying to provide such intentional explanations,

${ }^{12}$ Fodor's failure to see this is not very easy to explain. The dialectical situation faced by the IRS defender seems to me entirely analogous to the one Fodorians would face if one complained that Fodor's own 1998 account of concept possession in terms of locking presupposes what it seeks to explain because for a subject to be locked to Cness in the way that is required for possessing $\mathrm{C}$ is for that subject to actually instantiate the mental representation for $\mathrm{C}$. This would do nothing to support an accusation of circularity, precisely because the notion of concept possession to be explained is not (and is far wider than) the notion of possession of a worldly related mental representation that appears in the explanans.

${ }^{13}$ This way of interpreting the Fodorian challenge is consonant with the responses to the 'Circularity Challenge' offered by some authors who articulate either a dispositional account (Weiskopf and Becthel 2004) or a pragmatist account (Prinz and Clark 2004) of inferential roles. As we are about to see, nothing of the sort is fairly required of a Rationalist IRS, even if a Rationalist IRS might be compatible with such reductive programs. 
the theorist opts for the wrong kind of explanatory reduction. Concept possession, when explained in intentional terms, can only be presupposed in a complexity that is as yet to be specified.

The response from the defender of Rationalist IRS seems to me to be quite straightforward. For, patently, the circularity objection cannot really require of a Rationalist IRS that it offer non-intentional explanations. It is clear that this kind of IRS does not and cannot provide such explanatory reduction. As we have seen (Section 1), IRS is committed to accounts of concept possession in terms of the instantiation of concept-individuating inferential roles. When these inferential roles are of the sort required in a Rationalist IRS, they can only be provided by reference to such intentional notions as propositional attitudes and cognitive value. In this context, the Fodorian objection is really just a rejection of the framework for a Rationalist IRS. Even worse, it seems to have its roots in the idea that possession conditions, as such, must not ever be characterized in terms of concept-individuating semantic notions, let alone inferentially articulated semantic notions. In other words, it amounts to an objection in terms of theoretical circularity, of precisely the sort we have seen cannot warrant a respectable accusation of circularity (see Section 3). The Rationalist IRS is a framework in which possession conditions are given in terms of semantic conditions. This version of the Fodorian objection therefore just begs the question against the IRS defender.

Fodorians who seek to mount a satisfactory circularity challenge to Rationalist IRS by appeal to the need for explanatory reduction to non-intentional categories face, in effect, another problem that is, I tend to think, simply disastrous for their strategy. For it is not only the case that the requirement for reduction to non-intentional notions would beg the question against the proponent of RIRs; in addition, there is very little reason to suppose that such explanatory reduction, if possible at all, would not be compatible with Rationalist IRS being true all the same. This story is in effect quite familiar and it tries to reuse some of Fodor's strongest contributions (see Rey 2004 for a similar line of argument). The idea is, briefly, that inferential roles identified at the intentional level in a Rationalist IRS could plausibly be the very same roles that a nonintentional story about concepts would reduce at the physical or mechanical level. The thesis that to possess a concept is to instantiate a certain inferential role at the intentional level is clearly reminiscent of (and indeed provides strong support for) the thesis that to possess a concept is to token a mental representation with a certain syntactic or causal role at the physical, realization level. According to this, the project of formulating a correct IRS for our concepts and the project of providing the correct causal chains for our mental representations could be understood as different parts of the general enterprise of devising a functional and naturalizing approach to the mind.

Difficulty in appreciating this point may come from the fact that the usual Rationalist IRS theories are clear examples of purely a priori reflection, and as such arguably insensitive to empirical information of the sort needed in such naturalizing accounts. However, the task of providing correct RIRs, and the associated Frege tests, can indeed be sensitive to all sorts of relevant empirical data. This should not be surprising since claims in Rationalist IRS are clearly counterfactual supporting. On the assumption that we have identified a candidate RIR* for C, our account is utterly vulnerable 
to considerations of the sort: if RIR* were not constitutive of having C, one should find people that reasonably count as having $C$ without their fulfilling RIR*. Or similarly, we would be sensitive to the reasoning that, if RIR* were really constitutive of having $\mathrm{C}$, one should not find people who lack $\mathrm{C}$ in spite of their conforming to RIR*. This is not to say that we should start conducting experiments in order to legitimate our IRS account, as if we should rely exclusively on verified data. We can however conceive of rationality more in accordance with the model of psychological facts than with the model of a priori theorizing. If that is true, nothing prevents Rationalist IRS accounts from being part of an overall empirical and naturalizing approach to the mind. ${ }^{14}$

These points can be summarized thus: it is one thing to explain concept possession by recourse to a notion that presupposes concept possession. It is quite another to explain concept possession by recourse to a notion of concept possession articulated in terms of rational inferential roles. The latter kind of account, but certainly not the former, involves explanations that are maximally informative and arguably part of empirical and naturalizing framework. If this line of reasoning is minimally sound, it shows that IRS, at least under the rationalist version I have been considering, is not fairly seen as falling prey to an unpalatable sort of explanatory circularity.

\section{Concluding remarks}

In this paper, I have undertaken the task of meeting the Fodorian 'Analyticity' and 'Circularity' challenges. When all is said and done, we can see that analyticity is not the real issue with regard to the former challenge. Apart from the orthogonal character of analyticity considerations, I have argued that an articulation of IRS in terms of Frege tests - what I have been calling a Rationalist IRS—equips us with a bona fide criterion for principled determination of public content-constituting inferences. As regards circularity, we have seen that, even if a theoretical kind of circularity can correctly be attributed to IRS - as in any other respectable field that relies on theoretical or empirical equivalences - it is not the case that it should also be attributed a vicious kind of explanatory circularity.

The question of whether we can successfully come up with a complete and fully satisfying IRS theory, no doubt, awaits further exploration. In the meantime, it is worth emphasizing that there is no problem of principle with an IRS account. It is consistent with all I have said here that, ultimately, it is some kind of informational view that will offer the best insight into the nature of concepts. The present point has

\footnotetext{
${ }^{14}$ Similar considerations can be brought into view so as to defend the idea that a Rationalist IRS can also benefit from the discoveries and results in the literature on judgment and decision making. Studies such as those carried out by Wason and Johnson-Laird, among many others, strongly suggest that humans are irrational in systematic ways. Far from being an obstacle for the statement of a Rationalist IRS, such studies can be extremely useful in providing empirical evidence about which possessionconstituting RIRs should be automatically discarded for the (rational but) real subject and about the precise nature and limits of human rationality for the purpose of formulating correct RIRs for concepts.
} 
been that this almost certainly will not be the case because IRS is unprincipled or circular.

\section{REFERENCES}

Bilgrami, Akeel. 1998. Why holism is harmless and necessary. Philosophical Perspectives 12: 105-26.

Block, Ned. 1986. Advertisement for a semantics for psychology. Midwest Studies in Philosophy 10: 615-78.

-. 1995. An argument for holism. Proceedings of the Aristotelian Society. New Series 94: 151-69.

Boghossian, Paul. 1993. Does an Inferential Role Semantics rest upon a mistake? Philosophical Issues 3: 7388.

- 1997. Analyticity. In Blackwell Companion to the Philosophy of Language, ed. Crispin Wright and Bob Hale. Oxford: Blackwell.

Brandom, Robert. 1994. Making it explicit: reasoning, representing, and discursive commitment. Cambridge, MA: Harvard University Press.

Burge, Tyler. 1986. Intellectual norms and the foundations of mind. Journal of Philosophy 83: 697-720.

Evans, Gareth. 1982. The varieties of reference. Oxford: Oxford University Press.

Field, Hartry. 1977. Logic, meaning, and conceptual role. Journal of Philosophy 74: 347-375.

Fodor, Jerry A. 1987. Psychosemantics. The problem of meaning in the philosophy of mind. Cambridge, MA: MIT Press.

—. 1998. Concepts. Where cognitive science went wrong. Oxford: Clarendon Press.

—. 2004. Having concepts: a brief refutation of the twentieth century. Mind \& Language 19: 29-47.

—. 2008. LOT2. The Language of Thought revisited. Oxford: Oxford University Press.

Fodor, Jerry A. and Ernest Lepore. 1991. Why meaning (probably) isn't conceptual role. Mind \& Language 6: 328-43.

—. 1992. Holism: A shopper's guide. Oxford: Blackwell.

Greenberg, Mark and Gilbert Harman. 2006. Conceptual Role Semantics. In Oxford Handbook of Philosophy of Language, ed. Ernest Lepore and Barry C. Smith, 295-322. Oxford: Oxford University Press.

Grice, Herbert Paul and Peter F. Strawson. 1956. In defense of a dogma. Philosophical Review 65: 141-58.

Grodzinsky, Yosef and Andrea Santi. 2008. The battle for Broca's region. Trends in Cognitive Sciences 12: 474-80.

Harman, Gilbert. 1974. Meaning and Semantics. In Semantics and Philosophy, eds. Milton K. Munitz and Peter K. Unger (New York: New York University Press). Reprinted in Reasoning, meaning, and mind, ed. Gilbert Harman, 192-205. 1999. Oxford: Oxford University Press.

-. 1987. (Nonsolipsistic) Conceptual Role Semantics. In New directions in semantics, ed. Ernest Lepore (London: Academic Press). Reprinted in Reasoning, meaning, and mind, ed. Gilbert Harman, 206-231. 1999. Oxford: Oxford University Press.

—. 1999. Reasoning, meaning, and mind. Oxford: Oxford University Press.

Higginbotham, James. 1998. Conceptual competence. Philosophical Issues 9: 149-62.

Horwich, Paul. 1998. Meaning. Oxford: Oxford University Press.

- 2005. Reflections on meaning. Oxford: Oxford University Press.

Loar, Brian. 1982. Conceptual role and truth conditions. Notre Dame Journal of Formal Logic 23: 272-83.

Mates, Benson. 1952. Synonymity. In Semantics and the Philosophy of Language, ed. Leonard Linsky, 111-36. Urbana, IL: University of Illinois Press.

McDowell, John. 1994. Mind and world. Cambridge: Harvard University Press.

McLaughlin, Brian P. 1993. On punctate content and on conceptual role, Philosophy and Phenomenological Research 53: 653-660.

Peacocke, Christopher. 1992. A study of concepts. Cambridge, MA: MIT Press.

—. 2000. Fodor on concepts: philosophical aspects. Mind \& Language 15: 327-40.

- 2002. Three principles of rationalism. European Journal of Philosophy 10: 375-97.

- 2004a. The realm of reason. Oxford: Clarendon Press.

—. 2004b. Interrelations: concepts, knowledge, reference and structure. Mind \& Language 19: 85-98.

- 2008. Truly understood. Oxford: Oxford University Press.

Pietroski, Paul. 2000. Euthyphro and the semantic. Mind \& Language 15: 341-49. 
Prinz Jesse and Andy Clark. 2004. Putting concepts to work: some thoughts for the twentifirst century, Mind \& Language 19: 57-69.

Putnam, Hilary. 1975. The analytic and the synthetic. In Mind, Language and Reality. Philosopbical Papers, Vol. 2, 33-69. Cambridge: Cambridge University Press.

Quine, Willard Van Orman. 1951. Two dogmas of empiricism. The Philosophical Review 60: 22-43.

-. 1960. Word and object. Cambridge, MA: Harvard University Press.

Rapaport, William J. 2002. Holism, conceptual-role semantics, and syntactic semantics. Minds \& Machines 12, 3-59.

Rattan, Gurpreet. 2008. Indeterminacy, a priority, and analyticity in the Quinean critique. European Journal of Philosophy 18: 203-26.

Rey, George. 2004. Fodor's ingratitude and change of heart. Mind \& Language 19: 70-84.

Rives, Bradley. 2009a. The empirical case against analyticity: two options for concept pragmatism. Minds \& Macbines 19: 199-227.

—. 2009b. Concept Cartesianism, concept pragmatism, and Frege cases. Philosophical Studies 144: 211-38.

Sober, Elliott. 2000. Quine. Proceedings of the Aristotelian Society 74: 237-80.

Verdejo, Víctor M. 2009a. Why rationalist compositionality won't go away (either). Theoria 24: 29-47.

- The rational and natural mind: from concepts to the Language of Thought. Dordrecht: VDM Verlag.

Wedgwood, R. 2007. The nature of normativity. Oxford: Oxford University Press.

Weiskopf, D. A. and Bechtel, W. 2004. Remarks on Fodor on having concepts. Mind \& Language 19: 4856.

Víctor M. Verdejo is a postdoctoral researcher at the Universidade de Santiago de Compotela, member of the GRECC Research Group (Grup de Recerca en Epistemologia i Ciències Cognitives) and associate member of the LOGOS Research Group. His work focuses mainly on the theory of concepts and concept possession, and the study of different approaches in the cognitive sciences. He has published in Journal of Philosophical Research, Review of Philosophy and Psychology and Teorema, among others.

AdDRESS: Departamento de Lóxica e Filosofía Moral, Universidade de Santiago de Compostela, Praza Mazarelos, P.C. 15782 Santiago de Compostela, La Coruña, Spain. E-mail: vmverdejo@gmail.com 